\title{
Regeneração periodontal em cães
}

\author{
Periodontal regeneration in dogs
}

\section{Emily Correna Carlo Reis ${ }^{I *}$ Andréa Pacheco Batista Borges ${ }^{I}$ Ricardo Junqueira Del Carlo}

\section{- REVISÃO BIBLIOGRÁFICA -}

\section{RESUMO}

A doença periodontal pode ser definida como a condição inflamatória dos tecidos de suporte do dente em resposta ao acúmulo do biofilme. A consequencia é a formação de graves defeitos ósseos, devido à perda dos tecidos periodontais, levando, em última instância, à perda dos dentes, predisposição a fraturas de mandíbula e formação de comunicações oronasais. O principal tratamento é a prevenção, incluindo a escovação dentária diária e a profilaxia periodontal, procedimento realizado pelo médico veterinário para remoção do biofilme e cálculo dentário acumulados. A recuperação dos tecidos perdidos, ou seja, a regeneração periodontal, é um processo mais complexo, pois envolve a formação de três tecidos intimamente ligados: osso alveolar, ligamento periodontal $e$ cemento. Assim, diversos materiais e técnicas foram e são constantemente desenvolvidos, incluindo membranas para regeneração tecidual guiada e a aplicação de enxertos $e$ biomateriais, amplamente estudados na odontologia humana e já disponíveis para aplicação na rotina clínica veterinária. Adicionalmente, novas possibilidades surgem com a associação dessas técnicas a fatores de crescimento e células-tronco e o desenvolvimento das membranas multifuncionais.

Palavras-chave: odontologia veterinária, doença periodontal, regeneração tecidual guiada, membranas multifuncionais.

\section{ABSTRACT}

Periodontal disease can be defined as the inflammatory condition of the tooth-supportive tissues as a response to biofilm accumulation. The consequence is the formation of severe bone defects due to the loss of periodontal tissues that ultimately lead to tooth loss, predispose to mandible fractures and formation of oronasal communications. The main treatment is prevention, including daily tooth brushing and periodontal prophylaxis, a procedure done by veterinaries to remove retained biofilm and calculus. Recovering lost tissues, i.e. periodontal regeneration, is a more complex process involving the formation of three tissues highly connected: alveolar bone, periodontal ligament and cementum. Therefore, several materials and techniques were and are constantly developed, including membranes for guided tissue regeneration and the application of bone grafts and biomaterials, widely studied in human dentistry and already available for veterinary practice. Additionally, new possibilities rise with the association of these techniques to growth factors and stem cells and the development of multifunctional membranes.

Key words: veterinary dentistry, periodontal disease, guided tissue regeneration, multifunctional membranes.

\section{INTRODUÇÃO}

A doença periodontal tem ganhado importância na medicina veterinária devido a suas graves consequências e alta prevalência em cães. Ela envolve a destruição dos tecidos que dão suporte ao dente, levando assim à formação de defeitos ósseos e perdas dos dentes, além de outras graves conseqências, como a formação de comunicações oronasais. Ainda, a doença periodontal afeta também a saúde sistêmica do animal.

'Departamento de Veterinária, Universidade Federal de Viçosa (UFV), Campus Universitário s/n, 36570-000, Viçosa, MG, Brasil. Email: emilycarlo@yahoo.com.br. *Autor para correspondência. 
Assim, a doença periodontal tem sido amplamente discutida em encontros e congressos nacionais e internacionais (MARRETA, 2001), sua forma de tratamento tem sido estudada e as técnicas disponíveis ampliadas. Inicialmente, a única opção de tratamento era a profilaxia periodontal com extrações dentárias. Em seguida, cirurgias gengivais começaram a ser empregadas visando a impedir a progressão da doença e, hoje, técnicas para regeneração periodontal são amplamente encontradas na literatura, chegando aos poucos à rotina clínico-cirúrgica. Dessa forma, cada vez mais, o médico veterinário deve estar ciente das novas opções de tratamento que estão em constante evolução.

Assim, o objetivo desta revisão foi contextualizar o problema, ou seja, a doença periodontal, seguido do seu tratamento com ênfase na mais recente opção, a regeneração periodontal. Esta revisão aborda os princípios da regeneração periodontal, apresentando uma importante parcela do que já foi realizado, o que está hoje disponível e quais são as tecnologias em desenvolvimento.

\section{DESENVOLVIMENTO}

\section{A Doença Periodontal}

O periodonto compreende os tecidos localizados ao redor do dente, dividido em periodonto de proteção que compreende a gengiva e o de sustentação, que corresponde ao cemento, ligamento e osso alveolar (HARVEY, 1998). A doença periodontal se inicia pelo acúmulo de bactérias imóveis, gram positivas e aeróbias na região cervical do dente, ou seja, a região da coroa dentária, que se localiza mais próximo ao sulco gengival, formando o biofilme (MARRETA, 2001; BRAGA et al., 2005). Em resposta a esse acúmulo, inicia-se um processo inflamatório no sulco gengival, com aumento da permeabilidade vascular (REYNOLDS \& MEIKLE, 1997) e infiltração de neutrófilos, seguidos de macrófagos e linfócitos (OHLRICH et al., 2009), levando à gengivite que já é clinicamente detectável. Se o acúmulo do biofilme persiste, bactérias predominantemente móveis, gram negativas e anaeróbias proliferam, persistindo a inflamação e liberação de citocinas e enzimas que levam à destruição dos tecidos periodontais, momento em que esse processo é chamado doença periodontal (WIGGS et al., 1998; BRAGA et al., 2005). Alguns dos mediadores do processo inflamatório são a interleucina 1 , o fator de necrose tumoral e a prostaglandina E. Dentre outras ações, esses mediadores estimulam osteoclastos e diminuem a proliferação de progenitores de osteoblastos, levando à reabsorção óssea (OHLRICH et al., 2009), e estimulam a síntese de metaloproteinases que agem na degradação do ligamento periodontal (REYNOLDS \& MEIKLE, 1997).
A doença periodontal tem ganhado importância por sua alta prevalência, com um dado consagrado entre os profissionais da área: $85 \%$ dos cães acima de três anos de idade apresentam doença periodontal, sendo esta a doença mais comum na espécie (HARVEY, 1998). Estudos no Brasil demonstraram prevalências que corroboram essa afirmativa, como o realizado por VENTURINE et al. (2007): 92,5\% dos cães examinados em clínica na grande São Paulo apresentavam algum grau de doença periodontal. É importante notar sua alta prevalência em animais idosos, uma vez que a doença pressupõe $o$ acúmulo do biofilme e, para que tal acúmulo e destruição do periodonto ocorram, um período de tempo de meses a anos é necessário. Além disso, a doença periodontal é mais prevalente em cães de raças de pequeno do que de grande porte, possivelmente devido a diferenças comportamentais e/ou maior frequência de pontos de contato entre os dentes nas raças pequenas, predispondo ao acúmulo do biofilme (HARVEY et al., 1994).

As consequências locais e sistêmicas da doença periodontal também contribuem para sua importância. Localmente, devido à destruição progressiva do periodonto, são formados sulcos gengivais mais profundos, chamados bolsas periodontais, permitindo o maior acúmulo do biofilme. Com a progressão da doença, a perda dentária é a consequência local mais comum, com prejuízo nas funções de preensão e mastigação de alimentos. Nos casos mais avançados da doença, nos quais existe grande reabsorção óssea, são comuns a formação de comunicações oronasais e a ocorrência de fraturas patológicas de mandíbula, principalmente, nos animais de raças pequenas (HARVEY, 1998; WIGGS et al., 1998). As fraturas patológicas de mandíbula são de especial importância por serem de difícil manejo clínicocirúrgico (LEGENDRE, 2003) e apresentarem prevalência considerável, correspondendo a $13 \%$ das etiologias de fraturas de mandíbula em estudo realizado no Brasil (LOPES et al., 2005).

A doença periodontal também apresenta efeitos sistêmicos, uma vez que o biofilme acumulado é uma constante fonte de bactérias que, penetrando na circulação sanguínea, pode afetar órgãos internos (HARVEY, 1998). A doença está associada a afecções cardíacas, pulmonares, articulares, renais e hepáticas (DeBOWE et al., 1996; BARBUDO-SELMI et al., 2004). Estudo realizado por PAVLICA et al. (2008) analisou alterações anatomopatológicas em cães e estimou que, para cada centímetro quadrado de tecido afetado pela doença, existe $40 \%$ mais chance de alterações cardíacas e renais estarem presentes, assim como $20 \%$ mais chance de alterações hepáticas existirem.

Ciência Rural, v.41, n.12, dez, 2011. 


\section{O tratamento}

A manutenção da saúde oral requer a escovação diária dos dentes, essencial para impedir o acúmulo do biofilme e o início da doença (LIMA et al., 2004). Quando já existe o acúmulo e a doença periodontal está instalada, o tratamento requer a remoção do biofilme e cálculo dentário, realizado em uma série de manobras agrupadas na profilaxia periodontal. Esta compreende a raspagem supra e subgengival (sulco gengival e bolsa periodontal), utilizando instrumentos manuais ou o ultrasom, aplainamento radicular, polimento das superfícies dentárias e lavagem do sulco gengival ou bolsa periodontal para remoção de debris (MARRETA, 2001).

Contudo, em muitos casos, a profilaxia periodontal deve ser complementada por diferentes técnicas. Um exemplo é o acesso cirúrgico às raízes de dentes com bolsas periodontais maiores do que $5 \mathrm{~mm}$ para efetiva descontaminação (HARVEY, 1998; WIGGS et al., 1998). São também utilizadas a gengivectomia e gengivoplastia, técnicas que eliminam parte da cobertura gengival que forma a bolsa periodontal, reduzindo sua profundidade e, consequentemente, o acúmulo de biofilme, facilitando a posterior escovação dentária (MARRETA, 2001). Apesar de efetivas na descontaminação local e na eliminação da inflamação, essas técnicas resultam na formação de um longo epitélio juncional que recobre a raiz dentária, associado a um tecido fibroso e à gengiva. Esses tecidos não são capazes de exercer as funções sensorial, nutricional e de suporte mecânico necessárias a um periodonto saudável. Portanto, ocorre reparação periodontal e não a regeneração, que deve compreender, por definição, a formação de novos cemento, ligamento periodontal e osso alveolar (CHRISTGAU et al., 2007).

A principal técnica desenvolvida para promover a regeneração periodontal é a regeneração tecidual guiada (RTG), na qual uma membrana de origem natural ou sintética é implantada entre a gengiva e a raiz dentária e osso alveolar expostos, cobrindo essas estruturas (WIKESJÖ et al., 1995; ARAÚJO et al., 1999; CHRISTGAU et al., 2007). Inicialmente, acreditava-se que células provenientes dos tecidos epitelial e conjuntivo da gengiva ocupavam o defeito periodontal rapidamente, formando um longo epitélio juncional e tecido fibroso, o que impediria a formação de novo osso, ligamento periodontal e cemento. Assim, as membranas agiriam bloqueando os tecidos da gengiva e permitindo a regeneração(ROBERT \& FRANK, 1994).

Atualmente, acredita-se que as membranas atuam estabilizando o coágulo sanguíneo na região do defeito e mantendo esse espaço até a migração das células progenitoras adequadas (WIKESJÖ et al., 2003; CHRISTGAU et al., 2007). Estudo clássico de
McCULLOCH et al. (1987) seguido de estudos posteriores, demonstraram que essas células progenitoras são as células-tronco mesenquimais, localizadas nas proximidades e ao redor dos vasos sanguíneos do ligamento periodontal e osso alveolar remanescentes, próximos ao defeito. Assim, essas células podem migrar e se depositar tanto ao longo da raiz dentária para a formação de novos cemento e ligamento periodontal quanto em todo o volume da matriz provisória para a formação de novo osso (ARAÚJO et al., 1999; IVANOVSKI, 2009).

Este conceito de "manutenção do espaço de um defeito" não é novo, ele já é amplamente conhecido na regeneração óssea e está mais recentemente sendo abordado na regeneração periodontal (WIKESJÖ et al., 2003). Assim, deve-se utilizar este conceito para a regeneração do osso alveolar, pois esse tecido necessita de um arcabouço na forma e volume adequados para sua regeneração, formado pela matriz provisória estável.

Nesse contexto, alguns autores testaram o preenchimento de defeitos periodontais com diferentes materiais osteocondutores. Contudo, acredita-se que no periodonto a estabilização do defeitoé importante também para que a matriz provisória se mantenha aderida à superfície da raiz dentária, influenciando grandemente na formação do cemento e ligamento periodontal (WIKESJÖ et al., 1995; WIKESJÖ et al., 2003).

Regeneração periodontal na odontologia veterinária

Pequeno é o número de trabalhos na Medicina Veterinária objetivando a regeneração periodontal. Aliado a isso, somente análises histológicas podem comprovar a regeneração dos três tecidos periodontais de suporte (ARAÚJO et al., 1999; CHRISTGAU et al., 2007) e alguns desses trabalhos não as realizaram.

Relatos de casos e estudos clínicos demonstraram bons resultados clínico-radiográficos, com a diminuição da bolsa periodontal pela redução do nível clínico de inserção (medido do fundo da bolsa periodontal até a junção cemento-esmalte) e aumento na radiopacidade e altura ósseas de defeitos periodontais. Foram utilizados nesses estudos o enxerto autógeno (SMITH, 1995), o biovidro particulado (DeFORGE, 1997), a associação da matriz orgânica de osso associada ao peptídeo sintético de adesão celular P-15 (FERRO \& GIOSO, 2009) e proteínas obtidas da matriz do esmalte (WATANABE et al., 2003). Os resultados permitem afirmar que houve melhora clínica resultante da formação de novo aparato de adesão ao dente, mas, visto que tal adesão pode ser proporcionada pelo longo epitélio juncional e tecido fibroso e não pelos tecidos periodontais (ARAÚJO et al., 1999; CHRISTGAU et al., 
2007), não se pode afirmar que houve regeneração. Portanto, a utilização dessas técnicas deve ser cautelosa e novos estudos são necessários para definir exatamente os tecidos formados com a utilização desses materiais.

Os resultados de trabalhos que analisaram histologicamente a regeneração periodontal são conflitantes. FÓFANO et al. (2005) e CARLO et al. (2006) analisaram membrana de colágeno em defeitos periodontais de tamanho padronizado no osso alveolar, sendo que os primeiros associaram-na à matriz óssea bovina mineralizada. Ambos observaram que os tratamentos propostos auxiliaram a regeneração alveolar no início do processo. Já SHOUKRY et al. (2007) não observaram benefício na utilização de enxerto ósseo autógeno associado à membrana amniótica canina, em comparação com apenas a profilaxia periodontal de rotina. Ainda, WATANABE et al. (2001) analisaram a formação de cemento, osso alveolar e ligamento periodontal utilizando proteínas da matriz do esmalte em um defeito apical após a apicectomia experimental, observando o favorecimento da regeneração. Provavelmente, esses estudos demonstraram resultados tão diferentes devido à diferença nos materiais utilizados e tipos de defeitos periodontais analisados, fatores preponderantes na comparação entre estudos de regeneração periodontal.

No cão e no homem, a doença periodontal apresenta muitos aspectos semelhantes, como sua etiologia e fisiopatologia (GIANNOBILE et al., 1994), os tecidos envolvidos, as características clínicas como a formação de bolsas periodontais (GIANNOBILE et al., 1994; WIKESJÖ et al., 2003), a morfologia dos defeitos ocorridos naturalmente e as características de reparação e regeneração (ARAÚJO et al., 1999; CHRISTGAU et al., 2007). Poucas características diferem, como, por exemplo, a ocorrência mais frequente de defeitos de furca classe III e o fato de a remodelação óssea ocorrer em velocidade aproximadamente um terço (1/3) mais rápida no cão em comparação com o homem (GIANNOBILE et al., 1994). Portanto, numerosos estudos em cães têm sido realizados utilizando-os como modelos experimentais, os quais fornecem as informações necessárias para a aplicação das técnicas de regeneração periodontal na clínica veterinária.

Regeneração tecidual guiada no modelo experimental cão A principal técnica estudada e utilizada para promover a regeneração periodontal é a regeneração tecidual guiada (RTG). Ela é algumas vezes associada a outros materiais, como o preenchimento do defeito com enxertos (MARDAS et al., 2003) ou materiais sintéticos (IVANOVSKI, 2009) e a aplicação de derivados da matriz do esmalte (WATANABE et al., 2003) ou fatores de crescimento (WIKESJÖ et al., 2003; IVANOVSKI, 2009).
Para a RTG, as membranas mais estudadas até o momento são as de politetrafluoretileno expandido (ePTFE), utilizadas com sucesso na regeneração periodontal e de uso predominante na odontologia humana. Trata-se de um material com propriedades mecânicas adequadas, pois é facilmente posicionado sobre o defeito periodontal, contornando suas bordas e ocluindo-as (RORIZet al., 2006; CHRISTGAU et al., 2007). Em geral, são capazes de manter o espaço do defeito dependendo da sua morfologia, como defeitos intraósseos com três paredes ósseas (WIKESJÖ et al., 2003). Para utilização naqueles defeitos que apresentam uma ou duas paredes ósseas e nos supra-alveolares, essas membranas estão também disponíveis reforçadas por estrutura ou tiras de titânio que mantêm a forma desejada, obedecendo o princípio de manutenção do espaço do defeito (PELED et al., 2002). Sua principal desvantagem é não ser reabsorvível, requerendo um segundo procedimento cirúrgico para sua remoção, tendo ainda o potencial de afetar os tecidos em regeneração (RORIZ et al., 2006).

Para superar esse problema, muitas membranas foram fabricadas com materiais reabsorvíveis comocolágeno (CIRELLI et al., 1997; CHRISTGAU et al., 2007), polidioxanona (CHRISTGAU et al., 2007), ácido polilático (ROBERT \& FRANK, 1994; AMANO et al., 2004; CHRISTGAU et al., 2007) e o ácido poli (láctico-coglicólico) (PGLA) (ARAÚJO et al., 1999). Um fator de essencial importância para o desenvolvimento de membranas reabsorvíveis é o tempo de reabsorção in vivo, que não deve ocorrer antes de oito a 12 semanas (CIRELLI et al., 1997). Estudos demonstraram que o tempo de reabsorção de membranas de colágeno variou de acordo com o processo de fabricação, estando em torno de quatro a 10 semanas (CIRELLI et al., 1997), sendo mais longo para as de ácido polilático, três a quatro meses (ROBERT \& FRANK, 1994).

Em geral, membranas reabsorvíveis apresentaram bons resultados depois que sua taxa de degradação foi estabelecida, obtendo resultados superiores aos obtidos apenas com a profilaxia periodontal (BOSSHARDT \& SCULEAN, 2009). CHRISTGAU et al. (2007) estudaram em cães a expressão de componentes da matriz extracelular na regeneração de defeitos de furca classe II (profundos, mas que mantêm a parede lingual), utilizando uma membrana nãoreabsorvível e três reabsorvíveis. A regeneração periodontal foi observada, sendo que o tipo de membrana não influenciou no padrão de expressão dos componentes e na regeneração dos tecidos periodontais. Contudo, a quantidade de regeneração foi negativamente influenciada pela contaminação destas e pela sua falta de estabilidade. 
De fato, a capacidade de manutenção do espaço do defeito dessas membranas é inadequada, com inúmeros relatos de colapso. Em geral, as membranas reabsorvíveis apresentam propriedades mecânicas desfavoráveis, de modo que a membrana aplicada sobre o defeito colapsa e ocupa o espaço que deveria manter. Isso prejudica a regeneração, sendo este um fator limitante para sua utilização(CIRELLI et al., 1997; CHANG \&YAMADA, 2000; WIKESJÖ et al., 2003; CHRISTGAU et al., 2007). Com o objetivo de impedir esse colapso, membranas reabsorvíveis foram utilizadas com fixações ao osso alveolar por pinos e parafusos, com bons resultados (AMANO et al., 2004).

Na tentativa de melhorar esses resultados, procurou-se incorporar antibacterianos às membranas ou associá-las aos fatores de crescimento e enxertos e biomateriais utilizados para o preenchimento de defeitos, com resultados variados. Como foi demonstrado que a contaminação bacteriana é um fator limitante para a regeneração periodontal, o metronidazol (KURTIS et al., 2002) ea doxiciclina (CHANG \& YAMADA, 2000; LYONS et al., 2008) foram incorporados a membranas reabsorvíveis de PGLA ou ácido poliláctico, objetivando a liberação lenta e constante desses antibacterianos. Contudo, o benefício deste tipo de associação em comparação com a membrana sem o antibacteriano foi demonstrado apenas no estudo que utilizou a doxiciclina em membrana de PGLA(CHANG \& YAMADA, 2000).

Assim, a RTG se mostrou uma técnica eficiente no tratamento de defeitos periodontais, indicada para a regeneração de defeitos de furca classe II e intra-ósseos de uma parede óssea, principalmente com a utilização de membranas. Defeitos de furca classe III e os supraalveolares devem ser tratados mais cautelosamente devido à dificuldade de regeneração.

Dessa forma, focando nesses defeitos de difícil regeneração, foi proposto o seu preenchimento com enxertos, autógeno ou alógeno, e biomateriais com base nos princípios da regeneração óssea (MARDAS et al., 2003; TAHERI et al., 2009). Os resultados são variáveis dependendo muito da morfologia do defeito periodontal (MARDAS et al., 2003; DUARTE et al., 2006; TAHERI et al., 2009; TSIOMIS et al., 2010). O preenchimento de defeitos de furca classe II com enxertos ou biomateriais não contribuiu para uma maior quantidade de tecidos regenerados, sendo frequente a ocorrência de anquilose e reabsorção da raiz dentária. Contudo, defeitos com morfologia menos favorável à manutenção do espaço, como os intra-ósseos com uma ou duas paredes ósseas e supra-alveolares, beneficiaram-se com opreenchimento com esses materiais, ocorrendo maior formação óssea (RORIZet al., 2006; TAHERI et al., 2009).
Diferentes substâncias foram utilizadas para favorecer a regeneração periodontal, também com resultados variáveis. As proteínas da matriz do esmalte em associação com membrana reabsorvível não proporcionou um aumento na quantidade de tecidos regenerados em relação ao uso apenas da membrana. Contudo, as características morfológicas do cemento na região apical do defeito se mostraram mais semelhantes às do cemento não afetado pela doença periodontal, incluindo a formação de ambas as camadas, celular e acelular do cemento (ARAÚJO et al., 1999). Já as associações de membranas com a proteína morfogenética óssea recombinante (rBMP-2) e com o fator de crescimento derivado de plaquetas demonstraram ser superiores à utilização apenas das membranas em defeitos de furca e supra-alveolares (PARK et al., 1995; WIKESJÖ et al., 2003). Esses defeitos são considerados de difícil regeneração, pois têm uma morfologia desfavorável à estabilidade da membrana, além de apresentarem pouco tecido ósseo remanescente próximo a eles, uma das fontes de células progenitoras para este processo.

A regeneração periodontal completa significa todos os tecidos formados nas regiões vestibular, lingual, mesial, distal e furca em extensão igual ao que existia antes da doença (WIKESJÖ et al., 2003; CHRISTGAU et al., 2007; BOSSHARDT \& SCULEAN, 2009). Contudo, apesar de todo o avanço das técnicas, membranas e biomateriais até aqui discutidos, essa completa regeneração periodontal ainda não é possível.

\section{Perspectivas}

A RTG já é amplamente utilizada na rotina odontológica humana. Entretanto, essa técnica caminha agora para outro estágio, no qual as membranas serão multifuncionais e não apenas com a função de estabilizar o defeito (INANÇ et al., 2009; PARK et al., 2009).

Diversos estudos realizados com biomateriais demonstraram a influência da topografia de superfície na regeneração óssea. Essa influência vai dos primeiros estágios, em que superfícies mais complexas aumentam a adesão de plaquetas e fibrina (PARK \& DAVIES, 2000; MENDES et al., 2009), até os estágios finais de deposição de matriz óssea, nos quais essas superfícies também favorecem a migração de osteoblastos, por meio da osteocondução (CHO et al., 2009). Assim, pesquisadores têm desenvolvido membranas com superfície interna apresentando topografia complexa, já que a que estará em contato com o defeito deverá favorecer a osteocondução e a que estará em contato com a gengiva deverá favorecer sua adesão (CHO et al., 2009).

Essas novas membranas estão sendo chamadas multifuncionais, porque sua estrutura física e constituição química são desenvolvidas para apresentar 
alguma das funções: oclusão da borda superior do defeito para impedir a migração do epitélio juncional na direção apical; maior adesão da gengiva à sua superfície externa, diminuindo assim a possibilidade de ocorrer recessão gengival; propriedades mecânicas adequadas à manutenção do espaço e estabilização da matriz provisória; favorecimento da osteocondução; além de serem reabsorvíveis (CHO et al., 2009; INANÇ et al., 2009; PARK et al., 2009).

A estrutura e constituição dessas novas membranas diferem bastante. Algumas membranas foram desenvolvidas com materiais poliméricos como o PGLA, em molde contendo ranhuras e sulcos de magnitude microscópica impressos em sua superfície (OWEN et al., 2005). Outras membranas foram fabricadas com nanofibras, com a combinação de diferentes biomateriais como o PGLA, a policaprolactona, nanotubos de carbono ehidroxiapatita (MEI et al., 2007; CHO et al., 2009). Outros pesquisadores optaram pela fabricação de membranas em duas ou três camadas com diferentes biomateriais, porosidades e espessuras, como a associação do PGLA com o ácido hialurônico (PARK et al., 2009).

Recentemente, este grupo de pesquisa desenvolveu duas membranas multifuncionais distintas, mas ambas objetivando a regeneração de defeitos periodontais de furca classe II experimentais em cães (CARLOREIS et al., 2010; CARLOREIS, 2011). A primeira foi fabricada com polihidroxibutirato e hidroxiapatita, completamente rígida, em que o desgaste foi utilizado para a adaptação à morfologia dos defeitos, contudo, não proporcionou regeneração significativa. A segunda foi constituída de PGLA e fosfato de cálcio, sendo também rígida, porém moldável aos defeitos após aquecimento e com a topografia da superfície interna altamente complexa. Análises histomorfométricas e à tomografia microcomputadorizada demonstraram significativa formação de novo osso alveolar, ligamento periodontal e cemento, sendo essa regeneração periodontal maior do que já conseguida com as membranas flexíveis tradicionais (CARLOREIS, 2011).

Nos últimos anos, a utilização de terapias celulares tem ganhado atenção, com diferentes abordagens. Uma opção é a engenharia de tecidos com o cultivo de células diretamente sobre a membrana a ser aplicada sobre o defeito periodontal, como em estudo que analisou a obtenção de células do ligamento periodontal e sua cultura em membranas de nanofibras de PGLA (INANÇ et al., 2009). Outra abordagem é o preenchimento do defeito periodontal pela aplicação direta de células-tronco mesenquimais, como nos recentes estudos de WEI et al. (2010) e LIU et al. (2010).

Células-tronco autógenas provenientes da medula óssea de cães foram cultivadas e aplicadas em defeitos periodontais agudos. Analisadas após seis semanas de tratamento, essas células foram observadas no osso alveolar, ligamento periodontal, cemento e vasos sanguíneos, exibindo marcadores de superfície típicos de osteoblastos e fibroblastos, mas a análise da quantidade de tecidos regenerados não foi realizada (WEI et al., 2010). De forma semelhante, LIU et al. (2010) utilizaram células-tronco do ligamento periodontal, com resultados semelhantes.

As membranas multifuncionais e a terapia com células-tronco são recentes e estão em desenvolvimento. Apesar de ainda não estarem disponíveis para a rotina clínico-cirúrgica, sua evolução deve ser acompanhada pelo médico veterinário devido aos resultados promissores demonstrados, possibilitando futuramente a utilização na regeneração periodontal.

\section{CONCLUSÃO}

Devido a gama de materiais utilizados e às diferentes morfologias de defeitos, a regeneração tecidual guiada apresenta resultados muito variáveis, mesmo assim, é a técnica que demonstrou os melhores resultados na regeneração periodontal até o momento. Atualmente, as membranas mais facilmente encontradas no mercado são as de politetrafluoretileno expandido, seguidas de algumas membranas reabsorvíveis e biomateriais para o preenchimento do defeito. Apesar de ainda não ser possível a completa regeneração do periodonto, importante regeneração periodontal e consequente melhora clínica pode ser conseguida com tais técnicas. Sendo assim, ainda são necessários estudos, observando-se boas perspectivas na utilização das membranas multifuncionais e na terapia com célulastronco.

\section{REFERÊNCIAS}

AMANO, Y. et al. Evaluation of a poly-lactic acid membrane and membrane fixing pin for guided tissue regeneration on bone defects in dogs. Oral Surgery Oral Medicine Oral Pathology Oral Radiology Endodontics, v.97, p.155-163, 2004. Disponível em: <http://www.sciencedirect.com/science/article/pii/ S1079210403005730>. Acesso em: 08 out. 2009. doi:10.1016/ j.tripleo.2003.09.009.

ARAÚJO, M.G. et al. Bone formation in furcation defects. An experimental study in the dog. Journal of Clinical Periodontology, v.26, p.543-652, 1999. Disponível em: <http:/ /onlinelibrary.wiley.com/doi/10.1034/j. 1600 051X.1999.261003.x/pdf>. Acesso em: 07 abr. 2010. doi: 10.1034/j.1600-051X.1999.261003.x.

BARBUDO-SELMI, G.R. et al. Periodontal disease characterization in dogs with normal renal function or chronic renal failure. Ciência Rural, v.34, n.1, p.113-118, 2004. Disponível em: <http://www.scielo.br/pdf/cr/v34n1/ 
a17v34n1.pdf>. Acesso em: 23 out. 2010. doi: 10.1590/S010384782004000100017 .

BOSSHARDT, D.D.; SCULEAN, A. Does periodontal tissue regeneration really work? Periodontology 2000, v.51, p.208219, 2009. Disponível em: <http://onlinelibrary.wiley.com/doi/ 10.1111/j.1600-0757.2009.00317.x/pdf>. Acesso em: 06 abr. 2010. doi: 10.1111/j.1600-0757.2009.00317.x.

BRAGA, C.A.S.B. et al. Isolamento e identificação da microbiota periodontal em cães da raça Pastor Alemão. Ciência Rural, v.5, n.2, p.385-390, 2005. Disponível em: <http://www.scielo.br/ pdf/cr/v35n2/a22v35n2.pdf $>$. Acesso em: 18 out. 2010. doi: 10.1590/S0103-84782005000200022.

CARLO, E.C. et al. Técnica da regeneração tecidual guiada (RTG) na reparação da mandíbula de cão. Revista Ceres, v.53, n.307, p.350-356, 2006.

CARLO REIS, E.C. et al. Regeneração de defeitos periodontais com membrana osteocondutora reabsorvível. In: CONGRESSO BRASILEIRO DE CIRURGIA E ANESTESIOLOGIA VETERINÁRIA, 9., 2010, Búzios, RJ. Anais... Búzios: Colégio Brasileiro de Cirurgia e Anestesiologia Veterinária, 2010. V.1, 217p. p.63-64

CARLO REIS, E.C. Desenvolvimento de membranas rígidas e reabsorvíveis e sua aplicação na regeneração periodontal. 2011. 102f. Tese (Doutorado em Medicina Veterinária) - Curso de Pós-graduação em Medicina Veterinária, Universidade Federal de Viçosa, MG.

CHANG, C.Y; YAMADA, S. Evaluation of the regenerative effect of a $25 \%$ doxycycline-loaded biodegradable membrane for guided tissue regeneration. Journal of Periodontology, v.71, p.1086-1093, 2000. Disponível em: <http://www.joponline.org/ doi/pdf/10.1902/jop.2000.71.7.1086>. Acesso em: 03 nov. 2009. doi: 10.1902/jop.2000.71.7.1086.

CHO, W.J. et al. Hydrophilized polycaprolactone nanofiber mesh-embedded poly(glycolic-co-llactic) membrane for effective guided bone regeneration. Journal of Biomedical Material Research, v.91A, p.400-407, 2009. Disponível em: <http:// onlinelibrary.wiley.com/doi/10.1002/jbm.a.32264/abstract>. Acesso em: 12 jan. 2010. doi: 10.1002/jbm.a.32264.

CHRISTGAU, M. et al. Extracellular matriz expression and periodontal wound-healing dynamics following guided tissue regeneration therapy in canine furcation defects. Journal of Clinical Periodontology, v.34, p.691-708, 2007. Disponível em: <http://dx.doi.org/10.1111/j.1600-051X.2007.01097.x>. Acesso em: 02 mar. 2009. doi: 10.1111/j.1600051X.2007.01097.x.

CIRELLI, J.A. et al. Evaluation of anionic collagen membranes in the treatment of class II furcation lesions: an histometric analysis in dogs. Biomaterials, v.18, p.1227-1234, 1997. Disponível em: <http://www.sciencedirect.com/science/article/pii/ S0142961297000537>. Acesso em: 10 abr. 2010. doi: 10.1016/ S0142-9612(97)00053-7.

DeBOWE, L.J. et al. Association of periodontal disease and histological lesions in multiple organs from 45 dogs. Journal of Veterinary, Dentistry, v.13, p.57-60, 1996.
DeFORGE, D.H. Evaluation of bioglass/perioglas ${ }^{\mathrm{TM}}$ (consil ${ }^{\mathrm{TM}}$ ) synthetic bone graft particulate in the dog and cat. Journal of Veterinary Dentistry, v.14, p.141-145, 1997.

DUARTE, T.S. et al. Osteointegração da hidroxiapatita sintética no processo alveolar da mantíbula de cães: aspectos histológicas. Revista Ceres, v.58, p.849-853, 2006.

FERRO, D.G.; GIOSO, M.A. Estudo clínico da aplicação de matriz inorgânica de osso associado a peptídeo sintético de adesão celular (MIO/P-15), PepGen P-15 ${ }^{\circledR}$, em lesões periodontais avançadas de cães. Pesquisa Veterinária Brasileira, v.29, p.109-116, 2009. Disponível em: <http://www.scielo.br/pdf/pvb/ v29n2/a04v29n2.pdf>. Acesso em: 10 dez. 2010. doi: 10.1590/ S0100-736X2009000200004

FÓFANO, G. et al. Aspectos histológicos da associação da matriz óssea bovina mineralizada com membrane de colágeno na reparação alveolar da mandíbula de cão. Revista Ceres, v.52, p.955-965, 2005.

GIANNOBILE, W.V. et al. Comparison of canine and nonhuman primate animal models for periodontal regenerative therapy: results following a single administration of PDGF/IGFI. Journal Periodontology, v.65,p.1158-1168, 1994.

HARVEY C.E. Periodontal disease in dogs: Etiopathogenesis, prevalence, and significance. Veterinary Clinics of North America: Small Animal Practice, v.28, p.1111-1128, 1998.

HARVEY, C.E. et al. Association of age and body weight with periodontal disease in north american dogs. Journal of Veterinary Dentistry, v.11, n.3, p.94-105, 1994.

INANÇ, B. et al. Periodontal ligament cellular structures engineered with electrospun poly(DL-lactide-co-glycolide) nanofibrous membrane scaffolds. Journal of Biomedical Materials Research, v.90A, p.186-195, 2009. Disponível em: <http://onlinelibrary.wiley.com/doi/10.1002/jbm.a.32066/ pdf>. Acesso em: 10 dez. 2010. doi: 10.1002/jbm.a.32066.

IVANOVSKI, S. Periodontal regeneration. Australian Dental Journal, v.54, n.1, p.S118-S128, 2009. Disponível em: <http:/ /onlinelibrary.wiley.com/doi/ 10.1111 /j. 1834 7819.2009.01150.x/pdf>. Acesso em: 04 abr. 2010. doi: 10.1111/j.1834-7819.2009.01150.x.

KURTIS, B. et al. Effect of polylactide/glycolide (PLGA) membranes loaded with metronidazole on periodontal regeneration following guided tissue regeneration in dogs. Journal of Periodontology, v.73, p.694-700, 2002.

LEGENDRE, L. Intraoral acrylic splints for maxillofacial fracture repair. Journal of Veterinary Dentistry, v.20, p.70$78,2003$.

LIMA, T.B.F. et al. Escova dental e dedeira na remoção da placa bacteriana dental em cães. Ciência Rural, v.34, n.1, p.155158, 2004. Disponível em: <http://www.scielo.br/pdf/cr/v34n1/ a23v34n1.pdf>. Acesso em: 23 out. 2010. doi:10.1590/S010384782004000100023

LIU, Y. et al. Periodontal ligament stem cell-mediated treatment for periodontitis in miniature swine. Stem Cells, v.26, p.10651073, 2010. Disponível em: <http://onlinelibrary.wiley.com/ doi/10.1634/stemcells.2007-0734/pdf>. Acesso em: 04 fev. 2011. doi: 10.1634/stemcells.2007-0734. 
LOPES, F.M. et al. Oral fractures in dogs of Brazil. Journal of Veterinary Dentistry, v.22, p.86-90, 2005.

LYONS, L.C. et al. Regeneration of degree II furcation defects with a 4\%doxycycline hyclate bioabsorbable barrier. Journal of Periodontology, v.79, p.72-79, 2008. Disponível em: <http:/ /www.joponline.org/doi/pdf/10.1902/jop.2008.070161>. Acesso em: 04 abr. 2010. doi: 10.1902/jop.2008.070161.

MARDAS, N. et al. Evaluation of a cell-permeable barrier for guided tissue regeneration combined with demineralized bone matrix. Clinical Oral Implants Research, v.14, p.812-818, 2003. Disponível em: <http://onlinelibrary.wiley.com/doi/ 10.1046/j.0905-7161.2003.00966.x/pdf>. Acesso em: 04 fev. 2011. doi: 10.1046/j.0905-7161.2003.00966.x.

MARRETA, S.M. Recognition and treatment of periodontal disease. In: THE ATLANTIC COAST VETERINARY CONFERENCE, 2001, New Jersey, USA. Proceedings... New Jersey: ACVC, 2001. Disponível em: <http://www.vin.com/ACVC/ 2001/>. Online. Acesso em: 06 abr. 2010.

McCULLOCH, C.A. et al. Paravascular cells in endosteal spaces of alveolar bone contribute to periodontal ligament cell populations. Anatomical Record, v.219, p.233-242, 1987.

MEI, F. et al. Improved biological characteristics of poly(1lactic acid) electrospum membrane by incorporation of multiwalled carbon nanotubes/hydroxyapatite nanoparticles. Biomacromolecules, v.8, p.3729-3735, 2007. Disponível em: <http://pubs.acs.org/doi/full/10.1021/bm7006295>. Acesso em: 24 fev. 2009. doi: 10.1021/bm7006295.

MENDES, V.C. et al. Discrete calcium phosphate nanocrystalline deposition enhances osteoconduction on titanium-based implant surfaces. Journal of Biomedical Materials Research, v.90A, p.577-585, 2009.

OHLRICH, E.J. et al. The immunopathogenesis of periodontal disease. Australian Dental Journal, v.4, n.1, p.S2-S10, 2009. Disponível em: <http://onlinelibrary.wiley.com/doi/10.1111/ j.1834-7819.2009.01139.x/pdf >. Acesso em: 11 dez. 2010. doi: 10.1111/j.1834-7819.2009.01139.x.

OWEN, G.R.H. et al. A PLGA membrane controlling cell behaviour for promoting tissue regeneration. Biomaterials, v.26, p.7447-7456, 2005.

PARK, J.Y.; DAVIES, J.E. Red blood cell and platelet interactions with titanium implant surfaces. Clinical Oral Implant Research, v.11, p.530-539, 2000. Disponível em: <http:// on linelibrary.wiley.com/doi/ $10.1034 /$ j. 1600 0501.2000.011006530.x/pdf >. Acesso em: 20 nov. 2009. doi: 10.1034/j.1600-0501.2000.011006530.x.

PARK, J.B. et al. Periodontal regeneration in class III furcation defects of beagle dogs using guided tissue regeneration therapy with platelet-derived growth factor. Journal of Periodontology, v.66, p.462-477, 1995.

PARK, J.K. et al. Guided bone regeneration by poly(lactic-coglycolic acid) grafted hyaluronic acid bi-layer films for periodontal barrier applications. Acta Biomaterialia, v.5, p.3394-4303, 2009. Disponível em: <http://onlinelibrary.wiley.com/doi/ $10.1034 / \mathrm{j} .1600-0501.2000 .011006530 . \mathrm{x} / \mathrm{pdf}>$. Acesso em: 03 abr. 2010. doi: 10.1016/j.actbio.2009.05.019.

PAVLICA, Z. et al. Periodontal disease burden and pathological changes in organs of dogs. Journal of Veterinary Dentistry, v. 25, p.97-105, 2008.

PELED, M. et al. Osseous reconstruction using a membrane barrier following marginal mandibulectomy: an animal pilot study. Journal of Periodontology, v.73, p.1451-1456, 2002.

REYNOLDS, J.J.; MEIKLE, M.C. Mechanisms of connective tissue matrix destruction in periodontitis. Periodontology 2000, v.14, p.144-157, 1997.

ROBERT, P.M.; FRANK, R.M. Periodontal guided tissue regeneration with a new resorbable polylactic acid membrane. Journal of Periodontology, v.65, p.414-422, 1994.

RORIZ, V.M. et al. Treatment of class III furcation defects with expanded polytetrafluoroethylene membrane associated or not with anorganic bone matrix/synthetic cell-binding peptide: a histologic and histomorphometric study in dogs. Journal of Periodontology, v.77, p.490-497, 2006.

SHOUKRY, M. et al. Periodontal repair of experimental plaqueinduced periodontal disease in dogs. Journal of Veterinary Dentistry, v.24, p.152-165, 2007.

SMITH, M.M. Treatment of a mandibular periodontal interproximal defect with a bone graft in a dog. Journal of Veterinary Dentistry, v.12, p.59-62, 1995.

TAHERI, M. et al. An evaluation of bovine derived xenograft with and without a bioabsorbable collagen membrane in the treatment of mandibular class II furcation defects. Australian Dental Journal, v.54, p.220-227, 2009. Disponível em: <http:/ /onlinelibrary.wiley.com/doi/ $10.1111 /$ j. 1834 7819.2009.01122.x/pdf>. Acesso em: 06 abr. 2010. doi: 10.1111/j.1834-7819.2009.01122.x.

TSIOMIS, A.C. et al. Avaliação histológica do biovidro particulado na reparação de defeito experimental em mandíbula de cães. Revista Ceres, v.62, p.80-85, 2010.

VENTURINI, M.A.F.A. et al. Doenças da cavidade oral atendidas no Centro Odontológico Veterinário durante 44 meses - estudo retrospectivo. Revista Nosso Clínico, v.10, p. 6-14, 2007.

WATANABE, K. et al. Efficacy of enamel matrix proteins on apical periodontal regeneration after experimental apicoectomy in dogs. Journal of Veterinary Medical Science, v.63, p.889894, 2001. Disponível em: <http://www.jstage.jst.go.jp/article/ jvms/63/8/63_889/_article/-char/en>. Acesso em: 06 abr. 2010. doi: $10.1292 /$ jvms.63.889.

WATANABE, K. Efficacy of enamel matrix protein applied to spontaneous periodontal disease in two dogs. Journal of Veterinary Medical Science, v.65, p.1007-1010, 2003. Disponível em: <http://www.jstage.jst.go.jp/article/jvms/65/9/ 65_1007/_article>. Acesso em: 06 abr. 2010. doi: 10.1292/ jvms.65.1007. 
WEI, N. et al. Auto-transplanted mesenchymal stromal cell fate in periodontal tissue of beagle dogs. Cytotherapy, v.12, p.514521, 2010. Disponível em: <http://informahealthcare.com/doi/ full/10.3109/14653241003709702>. Acesso em: 26 jul. 2010. doi: $10.3109 / 14653241003709702$.

WIGGS, R.B. et al. Oral and periodontal tissue. Maintenance, augmentation, rejuvenation and regeneration. Veterinary Clinics of North America: Small Animal Practice, v.28, n.5, p.1165-1188, 1998.
WIKESJÖ, U.M. et al. Dynamics of wound healing in periodontal regenerative therapy. Journal of the California Dental Association, v.23, p.30-35, 1995.

WIKESJÖ, U.M.E. et al. Periodontal repair in dogs: evaluation of a bioabsorbable space-providing macro-porous membrane with recombinant human bone morphogenetic protein-2. Journal of Periodontology, v.74, p.635-647, 2003. 